IZA DP No. 6557

Why Do People Pay for Useless Advice?

Implications of Gambler's and Hot-Hand Fallacies in False-Expert Setting

Nattavudh Powdthavee

Yohanes E. Riyanto

May 2012 


\title{
Why Do People Pay for Useless Advice? Implications of Gambler's and Hot-Hand Fallacies in False-Expert Setting
}

\author{
Nattavudh Powdthavee \\ London School of Economics, \\ University of Melbourne and IZA \\ Yohanes E. Riyanto \\ Nanyang Technological University \\ Discussion Paper No. 6557 \\ May 2012 \\ IZA \\ P.O. Box 7240 \\ 53072 Bonn \\ Germany \\ Phone: +49-228-3894-0 \\ Fax: +49-228-3894-180 \\ E-mail: iza@iza.org
}

Any opinions expressed here are those of the author(s) and not those of IZA. Research published in this series may include views on policy, but the institute itself takes no institutional policy positions.

The Institute for the Study of Labor (IZA) in Bonn is a local and virtual international research center and a place of communication between science, politics and business. IZA is an independent nonprofit organization supported by Deutsche Post Foundation. The center is associated with the University of Bonn and offers a stimulating research environment through its international network, workshops and conferences, data service, project support, research visits and doctoral program. IZA engages in (i) original and internationally competitive research in all fields of labor economics, (ii) development of policy concepts, and (iii) dissemination of research results and concepts to the interested public.

IZA Discussion Papers often represent preliminary work and are circulated to encourage discussion. Citation of such a paper should account for its provisional character. A revised version may be available directly from the author. 


\section{ABSTRACT \\ Why Do People Pay for Useless Advice? Implications of Gambler's and Hot-Hand Fallacies in False-Expert Setting ${ }^{*}$}

We investigated experimentally whether people can be induced to believe in a non-existent expert, and subsequently pay for what can only be described as transparently useless advice about future chance events. Consistent with the theoretical predictions made by Rabin (2002) and Rabin and Vayanos (2010), we show empirically that the answer is yes and that the size of the error made systematically by people is large.

JEL Classification: C91, D03

Keywords: gambler's fallacy, hot-hand, random streak, expertise, information

Corresponding author:

Nattavudh Powdthavee

CEP, London School of Economics

Houghton Street

London, WC2A 2AE

United Kingdom

E-mail: n.powdthavee@gmail.com

\footnotetext{
*We are grateful to Gigi Fosters, Paul Frijters, Jack Knetsch, Andrew Oswald, Marie-Claire Villeval for helpful comments on the draft. We also thank Liu Jia, Weerachart Kilenthong, and students and staffs at University of Thai Chamber of Commerce and Nanyang Technological University for their help in carrying out the experiments. The research was supported by the SUG grant provided by Nanyang Technological University, and was carried out whilst the first author was employed at Nanyang Technological University, Singapore.
} 
Why do humans pay for advice about the future when most future events are predominantly random? What explains, e.g., the significant money spent in the finance industry on people who appear to be commenting about random walks, payments for services by witchdoctors, or some other false-expert setting?

Traditional economists attribute such behaviors to random error in decision-making. This is the notion that an average person is disinclined to commit such errors, and that people rationally pay for advice only if it does not seem logically counterintuitive at the time of purchase but that is potentially useless ex post. By contrast, psychology literature assumes that human beings are hypersensitive at detecting agency, even when none exists, to help them to explain phenomenon that cannot be easily explained (see, e.g., Barrett, 2004). This implies that on average people will be happy to pay for advice that is generally counterintuitive to their objective reasoning if they believe there is an intelligent agent making the decisions for them. Such an apparent divide between the two social-science disciplines is scientifically unattractive.

Our paper focuses on a situation in which there is true randomness and predictions are transparently useless. In this setting of non-existent expertise, can an average individual be convinced to switch from having the correct belief that "outcomes are independent and predictions are inherently useless" to the false belief that "predictions provide useful information about the future" - thus leading them to buy subsequent predictions in the future - if they had recently observed a streak of perfect predictions being made in front of them live? We found that the answer is yes and that the size of the error made systematically by people is large.

\section{Background}

There is little economic theory in this area. Rabin (2002) and Rabin and Vayanos (2010) outline a model in which believers of "the law of small numbers" - i.e. those who believe that a small sample of signals represents the parent population from which it is drawn (Tversky \& Kahneman, 1971) - will be willing to pay for services by financial analysts after observing randomly occurring streaks of profitable financial performances predicted by these professionals. This fallacious belief in the hot-hand of a financial expert arises as a consequence of the gambler's fallacy, which is defined as an individual's tendency to expect outcomes in random sequences to exhibit systematic reversals. The authors suggest that an investor who believes that the performance of a mutual fund is a combination of the 
manager's ability and luck will, at first, underestimate the likelihood that a manager of average ability will exhibit a streak of above- or below-average performance. Following good or bad streaks, however, the investor will revert to overestimate the likelihood that the manager is above or below average, and so in turn will over-infer that the streak of unusual performance will continue (see also Gilovich et al., 1985). The implication of this is that believers of the law of small number will be happy to pay for real-time price information provided by experts, such as stockbrokers or managers of actively-managed funds, even when it is well-documented that actively-managed funds do not outperform their market benchmark on average (see, e.g., Fama, 1991).

By contrast, psychologists have a general model to explain the widespread of humans' belief in invisible agents or non-existent expertise. The psychologist Justin Barrett (2004) hypothesizes that, in order to survive and reproduce, humans have evolved to be hypersensitive to detecting agency even when there is none; e.g., it is far better to avoid several imaginary predators than be eaten by a real one. According to this hypersensitive agency detection device (or HADD) hypothesis, HADD is set off by various ambiguous environmental stimuli, such as recent observations of good or bad streaks of chance events, and when triggered, HADD produces beliefs in unseen agents who are presumed to be the cause of such ambiguous stimuli, such as spirits or supernatural agents.

Econometric evidence is also scarce. One reason for this is because much of the empirical literature in this field focuses on non-expert setting and explores only an average person's reactions to streaks of signals in truly random events. For example, Offerman and Sonnemans (2004) find laboratory evidence consistent with the idea of hot-hand fallacy in their experiments of coin-flipping. The authors demonstrate that subjects tend to believe that the evidence that a randomly-drawn coin is "biased" is stronger, the longer the length of a streak it generates. Croson and Sundali (2005) find evidence of gamblers in casino behaving in such a way that is consistent with both the gambler's and hot-hand fallacies. The authors show that, in a game of roulette, casino gamblers tend to bet against a sufficiently long streak rather than with a streak (the gambler's fallacy), whilst at the same time tend to bet on more numbers after winning than after losing (the hot-hand fallacy). Using a computerized roulette game, Ayton and Fischer (2004) show that subjects tend to believe in the gambler's fallacy with respect to the sequence of outcomes of the roulette wheel. Yet when the subjects' role was to predict the outcomes of the roulette wheel, they tend to over-predict how well or badly they would do at predicting based on their previous streak of predictions, i.e. the hot-hand effect. Guryan and Kearney (2008) present evidence of the hot-hand effect in stores that sell 
lotto numbers. The authors show that the week following the sale of a large-prize winning ticket, the winning store experiences a significant increase in relative sales for the winning lotto game. Using a unique panel data of lottery players, Jørgensen et al. (2011) find evidence that while most lottery players tend to pick the same set of numbers week after week without regards of the numbers drawn in the lotto in previously weeks, for the people who do change they do so in such a way that is consistent with the law of small numbers. On average, these "switchers" move away from numbers that have been recently drawn (the gambler's fallacy), and move towards numbers that are on streak (the hot-hand fallacy). But currently the economics literature is small. In particular, evidence of people paying for an expert's prediction, even when none exists, is virtually non-existent and the extent of such behavior is imperfectly understood.

\section{Experimental framework}

To investigate whether people are susceptible to the gambler's and hot-hand fallacies in a transparently false-expert setting, a series of laboratory experiments was conducted on volunteered participants in Thailand and Singapore. We ran our first set of experiments in Thailand in December 2011, and the randomly selected participants were Undergraduate students at the University of Thai Chamber of Commerce (UTCC) and Chulalongkorn University in Bangkok $(N=177)$. We then ran our second set of experiments in Singapore in March 2012. Here, the volunteered participants came from randomly drawn Undergraduate students at the Nanyang Technological University $(N=201)$. Overall, participants came from different schools and faculties, including humanities and social sciences, engineering, sciences, and business and accounting. We ran twelve sessions in total (four in Thailand, and eight in Singapore), and were able to recruit around 45 people per session in Thailand and 30 people per session in Singapore.

Participants were randomly assigned to cubicles as they entered the labs. They were then told that there would be two tasks for them to complete. The first task will involve in participants placing bets on the outcomes of five rounds of "fair" coin flips. To ensure the fairness of the coin used in the experiment, we told participants the followings:

(i) The coins will not come from the experimenters but from the participants,

(ii) The coins used in the flips will be changed after the $2^{\text {nd }}$ and $4^{\text {th }}$ flip,

(iii) It will be the volunteered participants who will be flipping the coin rather than one of the experimenters, and 
(iv) The coin-flipper will be changed in every round.

Each participant was given an initial endowment with which to make their bets in the five rounds of coin flips. There was a minimum bet of 10 tokens per round, and participants were not allowed to go bankrupt before the final round was reached. Participants in Thailand were given an initial endowment of 100 tokens. Since there were a few participants who went bankrupt before the final round in Thailand, we decided to give each participant a higher endowment level of 300 tokens at the start of the experiment when we ran it in Singapore. Placing a correct bet is worth double and an incorrect one is worth zero in return. Each participant was also given at the beginning of the experiment five numbered envelopes which were taped on each cubicle's table. Contained within it was a "prediction" of the coin flip that had not happened yet in each of the numbered rounds. In each round, participants would be given an opportunity to pay a fixed price of 10 tokens to see the inside of the corresponding numbered envelope before a bet was placed and the coin flipped. If participants decided not to pay, they would then be invited after the flip to view for free whether the prediction actually matched the outcome. In addition to this, great care was taken not to provide any misleading information, e.g., who made the predictions or how the predictions were generated, etc., which could potentially prime participants into buying (or not buying) the predictions.

To guarantee a significant number of participants receiving at least four consecutive correct predictions in five rounds of fair coin flips, predictions were generated and assigned in such a way that approximately $1 / 2$ of $N$ received one correct prediction after Round $1,1 / 2 \times 1 / 2$ of $N$ received two correct predictions after Round 2, etc. (see Fig.1). This method of randomization-in-randomization - i.e., the process of randomizing people within the same session into control and treatment groups - made sure that at least 1 out of $N$ participants per session will randomly receive all correct predictions irrespective of the actual outcomes of the coin flips. Of the total number of 378 participants from two countries, 191 received a correct prediction in the first round; 92 received all-correct predictions after the first two rounds; 48 after the first three rounds; and 23 after the first four rounds of coin flips. ${ }^{1}$

The second task of the experiment involved participants completing a set of probability test (which was incentivized with each correct answer given $=$ SG\$0.20), as well as a set of standard control questionnaire. At the end of the experiment, all participants were

\footnotetext{
${ }^{1}$ The method was first seen on a UK TV show in 2008 which was demonstrated by a British magician, Derren Brown. In his program called "The System", Derren Brown used this method to show how he was able to predict, for one particular person, six consecutive wins at the horserace.
} 
debriefed on the nature of the experiment either immediately (Thailand) or later via email (Singapore). Descriptive statistics are summarized in Table A in the appendix.

\section{Econometric specification}

To uncover whether a streak of past predictions matter to the subject's purchasing decision of in the current round of coin flip, we estimate the following econometric specification separately for round $j=\{2,3,4,5\}$ :

$b_{i j}=\alpha+\beta_{j} p_{i(j-1)}+\varphi_{j} s_{i(j-k)}+\delta_{j} b_{i(j-k)}+\lambda_{j} w_{i(j-k)}+\sigma_{j}\left(b_{i(j-k)} \times w_{i(j-k)}\right)+X_{i}^{\prime} \gamma_{j}+\varepsilon_{i j}$,

where $i$ indexes individual, $k$ indexes the number of rounds prior to round $j, b$ is an indicator variable representing whether the subject paid 10 tokens to see the prediction in round $j, p$ is a set of dummy variables representing a streak of successful or failed predictions in round $j-k, s$ is a set of dummy variables indicating a streak of outcomes of previous coin flips, i.e., whether previous outcomes have all been Heads $(\mathrm{H})$ or Tails $(\mathrm{T}), w$ is a set of indicator variables representing the subject has made an incorrect bet in round $j-k, X$ is a vector of control variables, including gender, nationality, the proportion of correct answers in the incentivized probability test, and endowment in round $j, \alpha, \beta, \varphi, \delta, \lambda, \sigma$, and $\gamma$ are parameters to be estimated, and $\varepsilon$ is the error term.

Our key parameter of interest is $\beta$, which represents the effect of observing successful (or failed) streaks of past predictions on the subject's buying decision in round $j$. Note that, for $j=2$, the estimated effect of getting a correct prediction in Round 1 is the effect relative to getting an incorrect prediction in Round 1. For $j=\{3,4,5\}$, the estimated effect of getting all correct, as well as incorrect, predictions prior to round $j$ is thus the effect relative to getting some correct and some incorrect signals, which is typically the outcomes subjects a priori expected to see for predictions made on truly random events. The parameter $\varphi$ represents the estimated effect of observing a streak of outcomes of coin flips for round $j=\{3,4,5\}$, and is expected to be negative in the buying equation, i.e., the subject's willingness-to-pay for a prediction should be lower if one of the two signals of the actual outcomes of coin flips $(\mathrm{H}$ or T) is observed repeatedly. The parameters $\delta$ and $\lambda$ represent the main effects of previous purchasing decisions and whether an incorrect bet was placed in round $j-k$, while the interaction coefficient $\sigma$ indicates the effect of buying a prediction but placing an incorrect 
bet in round $j-k$. Here, we would expect both $\delta$ and $\lambda$ - i.e., the effects of "buying and placing a correct bet in round $j-k$ " and "not buying and placing an incorrect bet in round $j-k$ " - to exhibit a positive sign, and $\sigma-$ the effect of "buying and placing an incorrect bet in round $j-k$ " to be negative. Finally, given that we randomly generate the control and treatment groups within the experiment itself by flipping coins, we can expect the covariance between $p_{i(j-1)}$ and the error term to be zero, i.e., $p_{i(j-1)}$ is i.i.d.

Empirically, we could also test whether the paid-for predictions were treated seriously by the subjects who bought them. Here, a natural question is whether the amount of endowment used in each bet is larger among buyers than non-buyers on average. The hypothesis can be tested by estimating the following specification for round $j=\{2,3,4,5\}$ :

$$
g_{i j}=\psi_{j}+\omega_{j} p_{i j}+\pi_{j} g_{i(j-k)}+\eta_{j} b_{i(j-k)}+\zeta_{j} w_{i(j-k)}+\rho_{j}\left(b_{i(j-k)} \times w_{i(j-k)}\right)+X_{i j}^{\prime} \tau_{j}+v_{i j},
$$

where $g$ denotes the $\log$ of the endowment amount used to bet by individual $i$ in round $j$, and $p$ is a dummy variable indicating whether the prediction was bought by the subject in round $j$. Assuming that buyers will tend to treat the paid-for predictions seriously and consequently placing larger bets than non-buyers, we would expect to see the estimated parameter $\omega$ to be positive and statistically significant for $j=\{2,3,4,5\}$.

\section{Results}

\section{A. What Makes People Pay For Useless Information?}

Did people who randomly received correct predictions perceive in a hot hand of the nonexistent expert and in turn pay for such useless information later? If so, how long was it before they started buying? The answers are: yes, and not long. Table 1 presents the results from a linear probability model estimation of equation (1) on pooled Thai and Singaporean data set, while Figure 2 presents a graphic representation of Table 1's results. Robust standard errors are calculated and reported in the table.

On average, the probability of buying the prediction in Round 2 for people who received a correct prediction in Round 1 was 5 percentage points higher than those who previously received an incorrect prediction in Round $1(P=0.046)$. The effect is monotonic and well-defined; probabilities of buying were 15 percentage points $(P=0.000), 19$ percentage points $(P=0.000)$, and 28 percentage points $(P=0.000)$ higher in Rounds 3,4 , and 5 for 
subjects whose previous predictions had all been correct relative to those whose previous predictions had been a combination of successes and failures. The results are robust the controlling for previous buying decisions, as well as the subject's ability to calculate probabilities under time pressure. ${ }^{2}$

While the gaps in the probabilities of buying between subjects whose previous predictions had all been incorrect and those in the reference group were statistically insignificantly different from zero for $j=\{3,4\}$, we were able to uncover some statistical evidence of the gambler's fallacy for $j=5$; the estimated average effect of receiving four consecutive incorrect predictions on the decision to buy in the final round was approximately 14 percentage points $(P=0.060)$. After observing four consecutive incorrect predictions, which has the same probability as observing four consecutive correct predictions, we find weak evidence of individuals perceiving that the expert's luck will eventually run out in the final round.

Juxtaposing the two sets of findings together offers two particularly interesting insights. The first is that observations of a short streak of successful predictions of a truly random event are sufficient to generate a significant belief in the hot hand of an agent; the perception which also did not revert even in the final round of coin flip. By contrast, the equally unlikely streak of incorrect predictions also generated a relatively weak belief in the existent of an "unlucky" agent whose luck was perceived to be likely to revert before the game finishes; evidence which was reflected in an increase in the subject's propensity to buy in the final round of coin flip.

One natural concern is whether the method of randomization-in-randomization employed in the experiment was successful at producing "clean" control and treatment groups. This can be easily checked. Figure 3 illustrates that there is statistically insignificant difference in the buying propensity in Round 1 between subjects who went on to receive a correct prediction and those who went on to receive an incorrect prediction in Round 2; a two sample $t$-test of equal means produces a $t$-statistics of $-0.9348(P=0.351)$. This suggests that the method of randomization-in-randomization was successful at generating clean control and treatment groups on average. It is also worth noting here the evidence of subjects paying to see the prediction in Round 1 - perhaps due to curiosity or subjects being unclear about the rules in the first round when the game was played for the first time.

\footnotetext{
${ }^{2}$ The decision to choose the linear probability model (LPM) over a probit (or logit) model is justified by the fact that the LPM estimates are readily interpretable as marginal effects. However, we find qualitatively similar results with similar trade-offs between variables are obtained using either probit or logit to estimate equation (1).
} 
Another objection is to do with the generalization of the above findings. Using a pooled data set that consists of samples drawn from two entirely different cultures, it is possible that our point estimates may have been primarily driven by the sample with a stronger pre-existing belief in invisible agents, e.g., the Thai people, perhaps much more so than any other populations, are generally known to have come from a culture that is heavily influenced by beliefs of spirituality and superstitions (see, e.g., Tanasornnarong et al., 2004). Additionally, the qualitative results may be different due to the different initial endowment levels assigned to participants in Thailand (100 tokens) and Singapore (300 tokens). To address this, Figures $4 \mathrm{~A}$ and $4 \mathrm{~B}$ re-do Figure 2 separately for the Thai and Singaporean samples. While it is true that the patterns are generally more robust for the Thai sample compared to the Singaporean sample, the general findings remain qualitatively the same. Subjects from both countries exhibited the buying behavior consistent with the hot-hand fallacy - this is the case even the cost of prediction is proportionately larger in Thailand than in Singapore, whilst evidence of the gambler's fallacy when only incorrect streaks of predictions had been observed is statistically significant at conventional levels only in the Thai sample.

Table 1's other results are also interesting in their own right. Looking across columns, we can see statistically insignificant differences in the propensity to buy by gender and nationality in every round. How good the subject was at calculating probabilities under time pressure and how much the subject had in terms of endowment at the start of each round did not seem to matter to the likelihood of buying the predictions. There is, however, some evidence that observing a streak of outcomes (all Hs or all Ts) had made a difference to the likelihood of buying in the final round of coin flip; subjects were approximately 12 percentage points $(P=0.000)$ significantly less likely to buy if they had observed either four Hs or four Ts prior to the final round. As expected, the buying decision was serially correlated with $\mathrm{AR}[1]$ on average. Controlling for streaks of correct and incorrect predictions, the decision to buy in round $j$ is positively and statistically significantly correlated with the decision to buy in round $j-1$. Nonetheless, the effect was cancelled out if the decision to buy in round $j-1$ was observed along with an incorrect bet being placed in the same round, e.g., for $j=5, P$ (buying prediction in $j \mid$ buying in $j-1$, placing an incorrect bet in $j-1)=0.432-$ $0.053-0.311=0.058(P=0.619)$. In other words, subjects quickly reverted to not buying in 
the current round after buying and subsequently making an incorrect bet in the previous round. $^{3}$

One question of interest is whether there is any interesting interaction effect between the previous streak dummies, $p_{i(j-1)}$, and the subject's personal characteristics, such as gender, nationality, and the statistics/probabilities test score. Though not reported here, we did not find statistically significant slope differences by gender, or nationality, or even the test score in the buying behavior among subjects who randomly received correct, as well as incorrect, predictions. In other words, we did not find the perceived hot hand effect (or evidence of the gambler's fallacy) to be statistically more pronounced for males compared to females, or the Singaporean sample compared to the Thai sample, or for those who scored better than others in statistics and probabilities on average. In short, there is no statistical evidence that some people are systematically more (or less) susceptible to the measured effects.

\section{B. Did Buyers Treat the Paid-for Predictions Seriously?}

One way to infer whether buyers treated the paid-for predictions seriously is to examine whether buyers bet more than non-buyers, on average. Table 2 reports the results from OLS estimation of equation (2) on the pooled data set. On average, the amount of bets buyers placed were around 30-40 percentage points higher in Rounds 3, 4, and 5 than non-buyers. The estimated effects are statistically significant at conventional levels, as well as robust to controlling for the current endowment level and previous buying decisions. These results provide strong evidence - of both statistical and economic significance - that buyers placed a significant level of trust on the paid-for predictions made by a perceived hot hand albeit nonexisting expert, rather than buying them to satisfy their own curiosity or for "fun".

\section{Concluding Remarks}

We conducted possibly one of the strongest laboratory tests on people's pre-existing beliefs to show that an average person is often happy to pay for what could only be described as transparently useless advice. We find, to the best of our knowledge, one of the first laboratory

\footnotetext{
${ }^{3}$ An opponent of our finding may argue that risk preference also matters as a control variable in our buying equation. After the experiment was run in Thailand, we decided to elicit subjects' risk preferences for the Singaporean sample. However, we find that it makes virtually no differences to the estimated $\beta$ parameter whether subjects' risk preferences were included as a control variable. This is not surprising, given that $p_{i(j-1)}$ is i.i.d.
} 
evidence that is consistent not only with the theoretical predictions made by Rabin (2002) and Rabin and Vayanos (2010), but also with Barrett's (2004) psychological model of "hypersensitive agency detection device". The reason for this is because, while it is not entirely logically implausible to explain a streak of good or bad performances by mutual-fund managers, it is perhaps significantly more counterintuitive to rationally explain how opening an envelope can possibly influence the outcome of a "fair" coin flip. It is thus arguable that the perceived hot hand of an expert in this particular setting is unfounded on many rational grounds, and modern economists may need to integrate this surprising finding into their theoretical models.

The buying behavior documented in this paper is also at odd with much of the previous findings in the representativeness literature (see, e.g., Tversky \& Kahneman, 1971; Gilovich et al., 1985; but perhaps with an exception of Guryan \& Kearney, 2008). According to the formalized model by Rabin and Vayanos (2010), the gambler's fallacy arises from an expectation that outcomes in random sequences will soon exhibit systematic reversals. What this implies is that, after witnessing a randomly occurring streak, it is possible for an individual to mistakenly infer unobserved heterogeneity from the observation of a streak and in turn form an erroneous belief in the hot hand. In other words, a surprising streak is required for a perceived hot hand to develop from the gambler's fallacy. Nonetheless, participants in our experiment did not require a surprising streak of correct predictions to believe in the hot hand of a non-existent expert. On the contrary, a significant proportion of subjects bought the prediction as early as Round 2 after observing a single correct prediction in Round 1.

In an attempt to explain this inconsistent finding, one could imagine that every individual began the experiment with a strong belief about how improbable it is to accurately predict outcomes of a series of coin flips. One such belief could be that it will take a long string of flipping coins before one could actually successfully predict five outcomes in a row. However, for approximately half of the subjects, this belief was challenged as early as the beginning of Round 2. Knowing that they will only get to observe coins being flipped four more times in the remaining rounds, as well as how improbable it is to accurately predict the outcomes of coin flips, the subjects may start believing in an agent that did not exist much faster than what previous economic models would predict. In other words, we speculate that the more improbable it is for an agent to get a streak of good performances (which is entirely different from randomly occurring streaks of outcomes in chance events), the easier it is for 
an individual to be "surprised" by a very short streak of random occurrences - or in our case after only one correct prediction.

Perhaps it is important to stress at this point that the intention of our study was not to create a false expert or a false-expert environment. Rather, it was to ensure that sufficient numbers of random streaks of correct and incorrect predictions of future events were observed to warrant a solid statistical analysis. At any rate, our experiment accurately describes how the real "false" experts typically operate in the information market, and the findings of this paper help to highlight how easy it is for an average person to form a belief in an expert when none may actually exist.

We began by noting a divide between the economic and psychological explanations of people paying for transparently useless advice. The above results seem to be more consistent with the predictions made by the recent formalization of the gambler's and hot-hand fallacies in the economics literature and the psychological concept of invisible agents, and away from the traditional economist's model of random error in the purchasing decision. More empirical evidence in this area is needed, however, before we can generalize the above results across different fault-expert settings. 


\section{References}

Ayton, Peter and Ilan Fischer. 2004. The hot hand fallacy and the gambler's fallacy: two faces of subjective randomness? Memory and Cognition, 32(8), 1369-1378.

Barrett, Justin L. 2004. Why would anyone believe in God? Walnut Creek, CA: AltaMira Press.

Croson, Rachel and James Sundali. 2005. The gambler's fallacy and the hot hand: empirical data from casinos. Journal of Risk and Uncertainty, 30(3), 195-209.

Fama, Eugene F. 1991. Efficient capital markets: II. Journal of Finance, 46, 1575-1617.

Gilovich, Thomas, Robert Vallone and Amos Tversky. 1985. The hot hand in basketball: on the misperception of random sequences. Cognitive Psychology, 17, 295-314.

Guryan, Jonathan and Melissa S. Kearney. 2008. Gambling at lucky stores: empirical evidence from state lottery sales. American Economic Review, 98(1), 458-473.

Jørgensen, Claus Bjørn, Sigrid Suetens and Jean-Robert Tyran. 2011. Predicting lotto numbers. CEPR Discussion Paper 8314.

Offerman, Theo and Joep Sonnemans. 2004. What's causing overreaction? An experimental investigation of recency and the hot-hand effect. Scandinavian Journal of Economics, 106(3), 533-553.

Rabin, Matthew. 2002. Inferences by believers in the law of small numbers. Quarterly Journal of Economics, 117(3), 775-816.

Rabin, Matthew; and Dimitri Vayanos. 2010. The gambler's and hot-hand fallacies: theories and applications. Review of Economics Studies, 77(2), 730-778.

Tanasornnarong, Nattaporn, Alun Jackson, and Shane Thomas. 2004. Gambling among young Thai people in Melbourne, Australia: an exploratory study. International Gambling Study, 4(2), 189-203.

Tversky, Amos and Daniel Kahneman. 1971. Belief in the law of small numbers. Psychological Bulletin, 76(2), 105-110. 
Figure 1: The coin tree

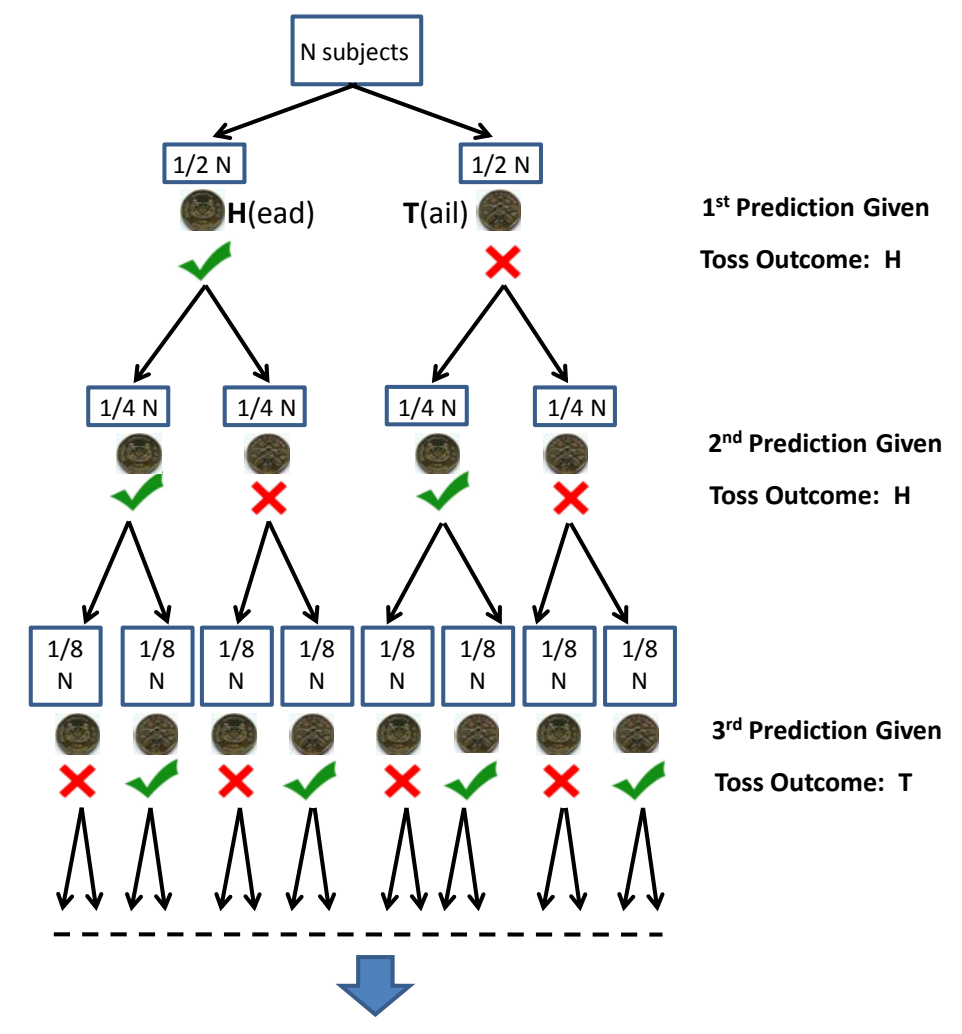


Table 1: Linear probability model estimates of factors determining the decision to buy a prediction in each round

\begin{tabular}{|c|c|c|c|c|}
\hline \multirow[b]{2}{*}{ Variables } & \multicolumn{4}{|c|}{ Bought prediction in round $j$} \\
\hline & $j=2$ & $j=3$ & $j=4$ & $j=5$ \\
\hline \multirow[t]{2}{*}{ All previous predictions had been correct } & $0.0522 * *$ & $0.153^{* * *}$ & $0.195^{* * *}$ & $0.276^{* * *}$ \\
\hline & {$[0.0260]$} & [0.0412] & [0.0668] & [0.0982] \\
\hline \multirow[t]{2}{*}{ All previous predictions had been incorrect } & & 0.00961 & 0.0245 & $0.145^{*}$ \\
\hline & & {$[0.0193]$} & {$[0.0365]$} & {$[0.0769]$} \\
\hline \multirow[t]{2}{*}{ Male } & -0.0191 & 0.0268 & -0.00223 & -0.0145 \\
\hline & {$[0.0273]$} & {$[0.0243]$} & {$[0.0264]$} & {$[0.0249]$} \\
\hline \multirow[t]{2}{*}{ Proportion of correct answers in probability test } & 0.0377 & -0.102 & 0.00118 & -0.0631 \\
\hline & {$[0.0540]$} & {$[0.0635]$} & {$[0.0565]$} & {$[0.0600]$} \\
\hline \multirow[t]{2}{*}{ Endowment in $j$ th round } & -0.000200 & -0.000295 & -0.000143 & $-7.07 \mathrm{e}-05$ \\
\hline & {$[0.000326]$} & {$[0.000203]$} & {$[0.000194]$} & {$[0.000120]$} \\
\hline \multirow[t]{2}{*}{ Streak of previous outcomes (all Heads or all Tails) } & & -0.0110 & -0.0199 & $-0.119 * * *$ \\
\hline & & {$[0.0368]$} & {$[0.0409]$} & {$[0.0391]$} \\
\hline \multicolumn{5}{|l|}{ Previous buying and betting behaviors } \\
\hline \multirow[t]{2}{*}{ Bought prediction in Round 1} & $0.265^{* * * *}$ & $0.145^{*}$ & 0.0903 & -0.0228 \\
\hline & {$[0.0868]$} & {$[0.0791]$} & {$[0.0712]$} & {$[0.0556]$} \\
\hline \multirow[t]{2}{*}{ Bought prediction in Round 2} & & $0.220^{*}$ & 0.164 & 0.135 \\
\hline & & {$[0.131]$} & {$[0.107]$} & {$[0.106]$} \\
\hline
\end{tabular}


Bought prediction in Round 3

Bought prediction in Round 4

Made incorrect bet in Round 1

Made incorrect bet in Round 2

Made incorrect bet in Round 3

Made incorrect bet in Round 4

Bought prediction Round 1 x Made incorrect bet Round 1

Bought prediction Round 2 x Made incorrect bet Round 2

Bought prediction Round 3 x Made incorrect bet Round 3

Bought prediction Round 4 x Made incorrect bet Round 4

Singaporean

$\begin{array}{cc}0.337 * * & -0.0623 \\ {[0.150]} & {[0.0904]} \\ & 0.423 * * * \\ & {[0.131]} \\ -0.0140 & 0.0196 \\ {[0.0292]} & {[0.0279]} \\ 0.0260 & -0.000254 \\ {[0.0345]} & {[0.0309]} \\ 0.0364 & -0.00670 \\ {[0.0361]} & {[0.0310]} \\ & -0.0530 \\ & {[0.0342]} \\ -0.112 & -0.0353 \\ {[0.0826]} & {[0.0607]}\end{array}$

$$
-0.249 * *
$$

$-0.179 * *$

[0.0799]

$-0.159$

$-0.0638$

[0.153]

[0.130]

[0.136]

$-0.317 *$

0.0840

[0.166]

[0.127]

$-0.311^{*}$

[0.179]

0.0523

0.0399

0.0188 


\begin{tabular}{lcccc} 
& {$[0.0758]$} & {$[0.0526]$} & {$[0.0460]$} & {$[0.0398]$} \\
Constant & 0.0197 & $0.144^{* *}$ & 0.0276 & $0.166^{*}$ \\
& {$[0.0683]$} & {$[0.0718]$} & {$[0.0693]$} & {$[0.0857]$} \\
\hline R-squared & 0.086 & 0.171 & 0.173 & 0.257 \\
Observations & 378 & 378 & 378 & 378 \\
\hline
\end{tabular}

Note: $*<10 \%$; $* *<5 \% ; * * *<1 \%$.

Dependent variable is a binary variable that takes a value of 1 if the subject paid to see the prediction in the corresponding numbered envelope, and 0 otherwise. Reference groups include: previous predictions had been a combination of both correct and incorrect predictions; female; nonstreak outcomes; did not buy prediction in round $j-k$; made wrong prediction in round $j-k$; and Thai. Robust standard errors are reported in parentheses. 
Figure 2: Proportion of prediction buyers by types of prediction streaks

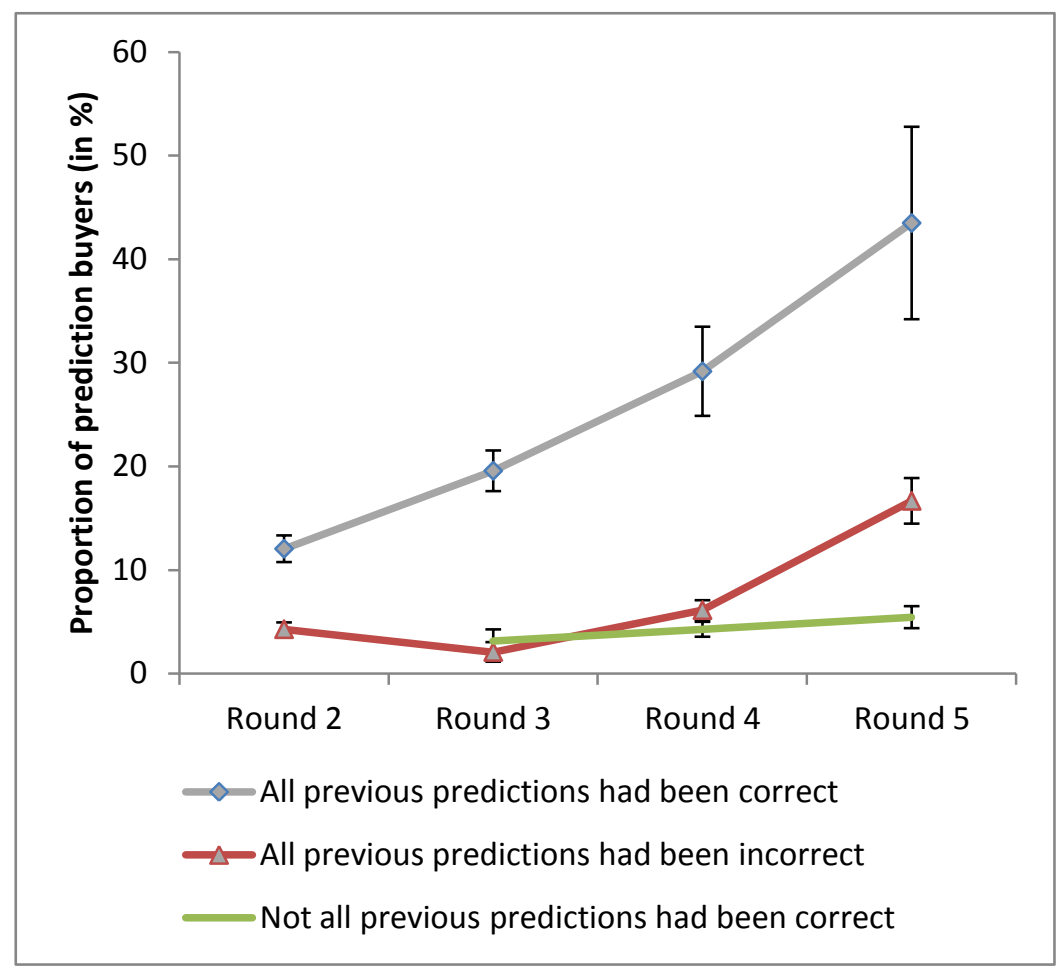

Note: These are regression-corrected means and standard errors obtained from Table 1. 4standard-error bands (95\% C.I.) are reported: two s.e. above and two below. 
Figure 3: Did luckier people buy more predictions in the $1^{\text {st }}$ round?

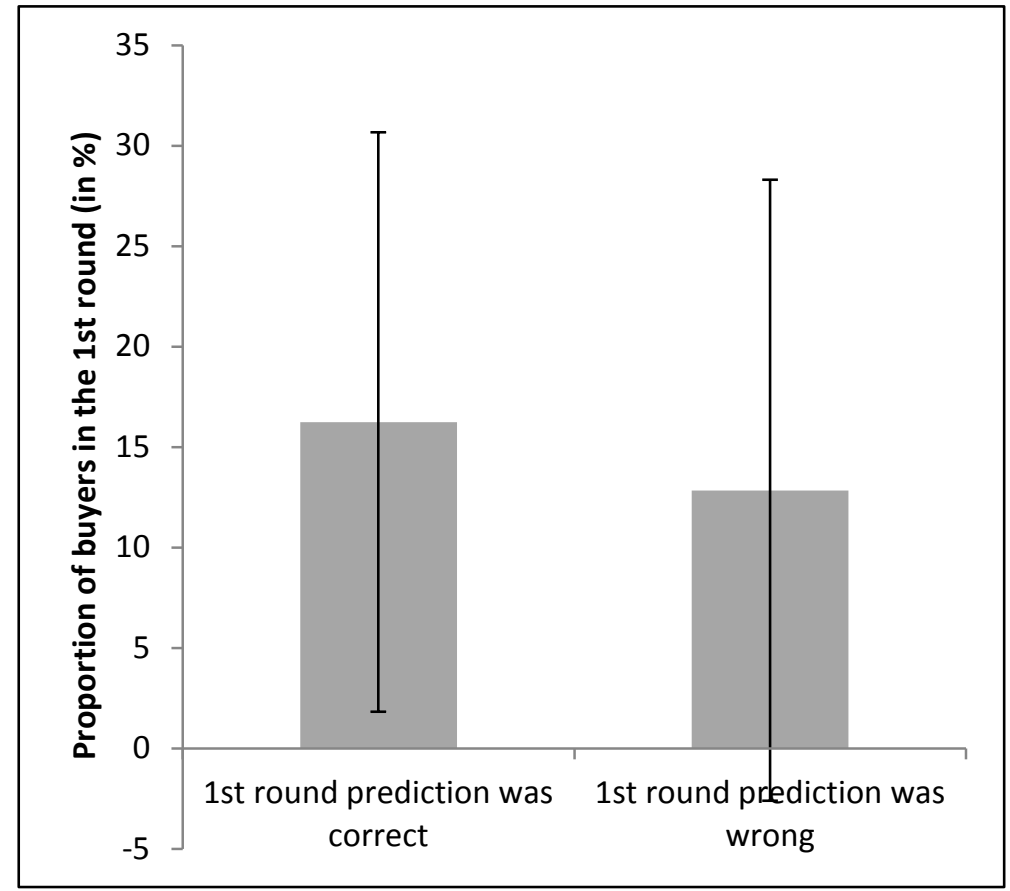

Note: These are regression-corrected means and standard errors; the regression controlled for all the variables displayed in the $1^{\text {st }}$ column of Table 1 . The dependent variable is a binary variable that takes a value of 1 if the subject paid to see the prediction in the first round, and 0 otherwise. 4-standard-error bands (95\% C.I.) are reported: two s.e. above and two below. 
Figures 4A-4B: Proportion of prediction buyers by types of prediction streaks and by nationality

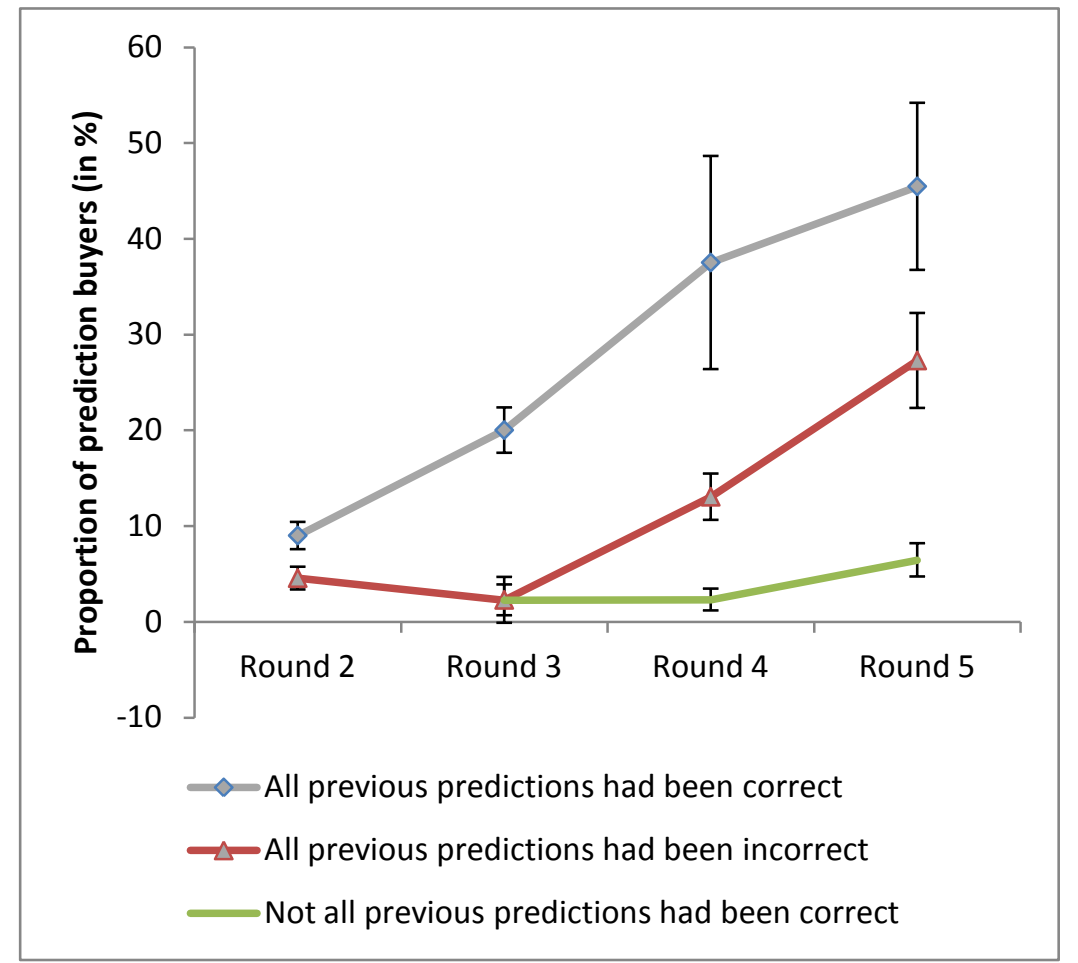

Figure 4A: Thai sample

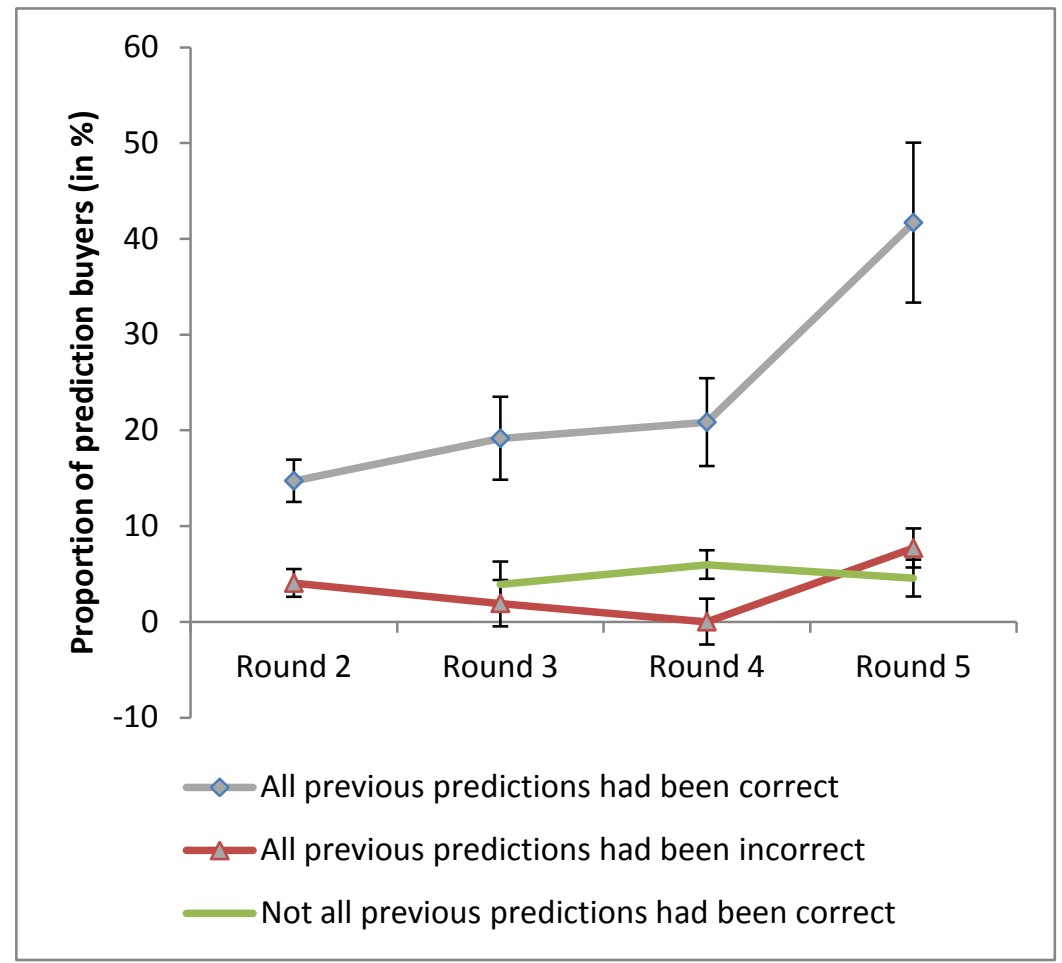

Figure 4B: Singaporean sample

Note: These are regression-corrected means and standard errors obtained from estimating equation (1) on the sub-samples. 4-standard-error bands (95\% C.I.) are reported: two s.e. above and two below. 
Table 2: OLS estimates of the log of bet amount placed in each round

\begin{tabular}{|c|c|c|c|c|}
\hline \multirow[b]{2}{*}{ Variables } & \multicolumn{4}{|c|}{ Log of bet amount in round $j$} \\
\hline & $j=2$ & $j=3$ & $j=4$ & $j=5$ \\
\hline \multirow[t]{2}{*}{ Bought prediction in round $j$} & 0.193 & $0.393^{* *}$ & $0.272 *$ & $0.429 * * *$ \\
\hline & {$[0.147]$} & {$[0.173]$} & {$[0.141]$} & {$[0.128]$} \\
\hline \multirow[t]{2}{*}{ Male } & 0.0205 & 0.0842 & -0.00466 & 0.0960 \\
\hline & {$[0.0630]$} & {$[0.0613]$} & {$[0.0587]$} & {$[0.0804]$} \\
\hline \multirow[t]{2}{*}{ Proportion of correct answers in statistical test } & 0.107 & 0.159 & 0.0628 & -0.0452 \\
\hline & {$[0.136]$} & {$[0.124]$} & {$[0.124]$} & {$[0.149]$} \\
\hline \multirow[t]{2}{*}{ Endowment in round $j$} & $-0.003 * * *$ & $-0.002 * * *$ & $-0.003 * * *$ & $-0.002 * * *$ \\
\hline & {$[0.000951]$} & {$[0.000576]$} & {$[0.000461]$} & {$[0.000452$} \\
\hline \multicolumn{5}{|l|}{ Previous buying and betting behaviors } \\
\hline \multirow[t]{2}{*}{ Bought prediction in round 1} & $0.279 * *$ & 0.0539 & 0.0654 & 0.176 \\
\hline & {$[0.140]$} & {$[0.133]$} & {$[0.130]$} & {$[0.192]$} \\
\hline \multirow[t]{2}{*}{ Bought prediction in round 2} & & 0.0656 & 0.128 & $-0.458 *$ \\
\hline & & {$[0.193]$} & {$[0.131]$} & {$[0.277]$} \\
\hline \multirow[t]{2}{*}{ Bought prediction in round 3} & & & 0.0641 & $-0.398 *$ \\
\hline & & & {$[0.231]$} & {$[0.239]$} \\
\hline Bought prediction in round 4 & & & & $0.272 *$ \\
\hline
\end{tabular}


Made wrong bet in round 1

Made wrong bet in round 2

Made wrong bet in round 3

Made wrong bet in round 4

Buy prediction round 1x Made wrong bet round 1

Buy prediction round $2 \times$ Made wrong bet round 2

Buy prediction round 3 x Made wrong bet round 3

Buy prediction round $4 \mathrm{x}$ Made wrong bet round 4

Singaporean

Constant
[0.141]

\begin{tabular}{|c|c|c|c|}
\hline$-0.856 * * *$ & $-0.293 * * *$ & $-0.414 * * *$ & $-0.337 * * *$ \\
\hline \multirow[t]{7}{*}[0.0971]{} & [0.109] & {$[0.0932]$} & [0.116] \\
\hline & $-1.011 * * *$ & $-0.671 * * *$ & $-0.430 * * *$ \\
\hline & [0.0867] & [0.106] & [0.136] \\
\hline & & $-0.737 * * *$ & $-0.425^{* * * *}$ \\
\hline & & {$[0.0798]$} & {$[0.115]$} \\
\hline & & & $-0.768 * * *$ \\
\hline & & & [0.0985] \\
\hline$-0.725 * * *$ & -0.162 & -0.261 & -0.375 \\
\hline \multirow[t]{7}{*}[0.177]{} & [0.193] & {$[0.184]$} & {$[0.251]$} \\
\hline & -0.0225 & $-0.499 * *$ & $0.635 *$ \\
\hline & {$[0.274]$} & {$[0.209]$} & {$[0.336]$} \\
\hline & & -0.221 & 0.432 \\
\hline & & {$[0.267]$} & {$[0.303]$} \\
\hline & & & $-0.707 * * *$ \\
\hline & & & {$[0.230]$} \\
\hline $0.885 * * *$ & $0.693 * * *$ & $0.638 * * *$ & $0.261 * *$ \\
\hline$[0.204]$ & {$[0.132]$} & {$[0.104]$} & {$[0.121]$} \\
\hline $1.996 * * *$ & $1.670 * * *$ & $1.762 * * *$ & $2.136 * * *$ \\
\hline [0.244] & [0.222] & [0.208] & {$[0.310]$} \\
\hline
\end{tabular}




\begin{tabular}{lcccc}
\hline R-squared & 371 & 370 & 370 & 367 \\
Observations & 0.384 & 0.554 & 0.597 & 0.500 \\
\hline
\end{tabular}

Note: $*<10 \% ; * *<5 \% ; * * *<1 \%$.

Dependent variable is log of the bet amount placed in round $j$. Robust standard errors are reported in parentheses. 
Table A: Descriptive statistics

\begin{tabular}{|c|c|c|c|c|c|}
\hline & \multicolumn{5}{|c|}{ Round } \\
\hline & $\mathbf{j}=\mathbf{1}$ & $\mathbf{j}=2$ & $\mathbf{j}=\mathbf{3}$ & $\mathbf{j}=4$ & $\mathbf{j}=5$ \\
\hline \multirow[t]{2}{*}{ Bought prediction } & 0.146 & 0.082 & 0.069 & 0.077 & 0.085 \\
\hline & $(0.35)$ & $(0.27)$ & $(0.25)$ & $(0.27)$ & $(0.28)$ \\
\hline \multirow[t]{2}{*}{ All previous prediction had been correct } & 0.505 & 0.243 & 0.127 & 0.061 & 0.026 \\
\hline & $(0.16)$ & $(0.24)$ & $(0.33)$ & $(0.43)$ & $(0.50)$ \\
\hline \multirow[t]{2}{*}{ All previous predictions had been incorrect } & & 0.254 & 0.130 & 0.063 & 0.032 \\
\hline & & $(0.44)$ & $(0.34)$ & $(0.24)$ & $(0.18)$ \\
\hline \multirow[t]{2}{*}{ Endowment level } & 206.34 & 203.11 & 200.93 & 202.96 & 201.41 \\
\hline & $(99.93)$ & $(107.92)$ & $(132.35)$ & $(132.61)$ & $(143.51)$ \\
\hline \multirow[t]{2}{*}{ Made incorrect bet } & 0.508 & 0.574 & 0.437 & 0.524 & 0.458 \\
\hline & $(0.50)$ & $(0.50)$ & $(0.50)$ & $(0.50)$ & $(0.50)$ \\
\hline \multirow[t]{3}{*}{ Streak of previous outcomes (all Hs or Ts) } & & & 0.714 & 0.188 & 0.127 \\
\hline & & & $(0.45)$ & $(0.39)$ & $(0.33)$ \\
\hline & Overall & & & & \\
\hline \multirow[t]{2}{*}{ Proportion of correct answers given in statistical test } & 0.736 & & & & \\
\hline & $(0.25)$ & & & & \\
\hline \multirow[t]{2}{*}{ Male } & 0.442 & & & & \\
\hline & $(0.50)$ & & & & \\
\hline \multirow[t]{2}{*}{ Singaporean } & 0.532 & & & & \\
\hline & $(0.50)$ & & & & \\
\hline
\end{tabular}

Note: Total N=378 (Thai: N = 177; Singaporean: N=201). 